(doctor, from Latin docere to teach), and the patient is less likely to be troubled by similar anxieties subsequently, with an appreciable saving of time for the doctor, and money for the Exchequer.

Otherwise, while some doctors run their practices, it will seem that some practices run their doctor.-I am, etc.

London S.E.20

DAvid Ryde

\section{Aetiology of Reye's Syndrome}

SIR,-I would like to report the case of a girl who died with Reye's syndrome while in complete remission from acute lymphoblastic leukaemia and to comment on possible aetiological implications of this association.

A 5-year-old girl had been in complete haematological remission on the Medical Research Counci UKALL I protocol, without C.N.S. prophylaxis, since the diagnosis of acute lymphoblastic leukaemia in October 1970. She had three episodes of menin geal leukaemia, each successfully treated with intrathecal methotrexate, the last, in March 1972 being followed by craniospinal radiotherapy. A further meningeal relapse in January 1973 was treated with intrathecal methotrexate. One week later she developed pancytopenia associated with epistaxes and pneumonia. She recovered with antibiotics and withdrawal of chemotherapy, and bone marrow remission was confirmed.

Pancytopenia recurred after restarting chemotherapy and again the drugs were stopped. Two days later she had a febrile cold and two further days later vomiting started and continued for 12 hours; her respiration became laboured and she became unconscious and flaccid with unreactive pupils, but she did not have fits. Until her death 12 hours later she had varying limb tone, tendon reflexes, and pupil responses, but no localizing neurological signs. She had mild hepatomegaly and was hypothermic. Terminally she had a large haematemesis.

Investigations showed haemoglobin $9 \cdot 7 \mathrm{~g} / 100 \mathrm{ml}$ platelets $10,000 / \mu \mathrm{l}$, neutrophils $12 \%(280 / \mu \mathrm{l})$, lymphocytes $83 \%(2000 / \mu \mathrm{l})$, myelocytes $5 \%$ $(120 / \mu 1)$. The blood film showed a picture of microangiopathic haemolytic anaemia. Prothrombin and partial thromboplastin times were prolonged and plasma factor $\mathrm{V}$ was reduced, but the thrombin time was normal. Plasma electrolytes: $\mathrm{Na} 143 \mathrm{mEq} / \mathrm{l}$., K $3.8 \mathrm{mEq} / \mathrm{l}$., total bicarbonate $6 \mathrm{mmol} / 1$; urea blood $19 \mathrm{mg} / 100 \mathrm{ml}$; serum bilirubin $2.5 \mathrm{mg}$ ! $100 \mathrm{ml}$; S.G.O.T. 744 I.U. l.; S.G.P.T. 558 I.U./1. Cerebrospinal fluid sugar $25 \mathrm{mg} / 100 \mathrm{ml}$; no white cells present. Full bacterial and viral cultures were negative.

Necropsy showed cerebral oedema, haemorrhagic gastric ulceration, a nutmeg liver, and dilatation of the right heart, but on microscopy fatty degeneration of the liver, renal tubules, and myocardium was confirmed without inflammatory or leukaemic infiltration in any organ.

Associations of Reye's syndrome with acute lymphoblastic leukaemia, microangiopathic haemolytic anaemia, and hypothermia have not been previously described. The unusual distribution of the fatty degeneration suggests a specific reaction to a single aetiological agent, and the evidence of Glick et al. ${ }^{1}$ supports a viral aetiology. The microangiopathic haemolytic anaemia may have been associated with the deposition of antigen-antibody complexes as we found no evidence of gross defibrination. Webb and Smith $^{2}$ have shown that viral infections in non-immune individuals may produce cerebral oedema alone, and the induced immunosuppression in treated acute lymphoblastic leukaemia may provide similar conditions for such a response.
Bone marrow depression in treated acute ymphoblastic leukaemia increases susceptibility to viral infection and may be exacer bated by it. It seems likely that both episodes of pancytopenia in our patient were aggravated in this way, and the observation by Olson et al. ${ }^{3}$ of thrombocytopenia in one patient with Reye's syndrome and pancytopenia in another may be a similar result of viral infection. I suggest that Reye's syndrome may represent an abnormal response to viral challenge in a patient with disordered immunity, whether hereditary or resulting from underlying disease or its treatment.-I am, etc.,

Hospital for Sick Children,

P. G. B. JohNSTON ondon W.C.1

Glick, T. H., Likosky, W. H., Levitt, L. P., 1970, 46, 371

Webb, H. E., and Smith, C. E. G., British

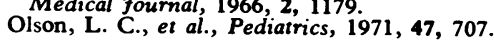

SIR,-I was interested in your excellen leading article (11 August, p. 308) in which you draw attention to this mysterious syndrome characterized by cerebral oedema without cellular infiltration or demyelination and fatty degeneration of the viscera, especially of the liver.

The cause of this disease, which affects children and carries a high mortality, is unknown. It may therefore be relevant to refer to studies in experimental animals in which an aseptic encephalitis and severe liver damage could be produced. ${ }^{1}$ We injected $0.3 \mathrm{ml}$ of a fine sterile emulsion of human bone marrow through the atlanto-occipital membrane into the thecal canal of rabbits. After an incubation period varying from a few days to three weeks a clinical picture developed which was characterized by paresis of the hind legs and spasmodic contractions of the neck muscles associated with bizarre movements of the head. In most animals these changes progressed and death occurred within a few days or weeks. In some of these rabbits the symptoms remained stationary or even disappeared. In contrast, when an equal amount of bone marrow obtained from rabbits or from guinea-oigs was injected intrathecally into rabbits no symptoms developed.

Independently and almost at the same time M. H. Gordon ${ }^{2} 3$ produced a very similar encephalitis in rabbits when he injected extracts made from lymphadenoma nodes into their brains. He assumed that his results supported a viral aetiology of lymphadenoma. Though the Gordon test proved to be of value in the diagnosis of this disease, our findings producing the same kind of encephalitis in rabbits with normal human bone marrow contradicted Gordon's evidence for a specific viral cause of lymphadenoma. Moreover, Gordon was not able to transmit the encephalitis from rabbit to rabbit. Likewise our attempts to do so in our animals were only partially successful.

In analogy to Reye's syndrome we found that severe liver damage was an outstanding feature in those rabbits which had developed encephalitis. Paraffin sections stained with haematoxylin and eosin showed the liver cells resembling plant cells rather than animal cells, the whole organ presenting a honeycomb-like appearance. When Best's stain was applied to the liver tissue massive deposits of glycogen were found.
No satisfactory explanation has so far been offered for this strange encephalitis in rabbits. However, some investigators in the U.S.A. and in other countries suggested that the presence of eosinophil cells in lymphadenoma nodes and in the human bone marrow may play a part in causing the encephalitis.

The fact that Reye's syndrome occurs only in children suggests that their bloodspinal fluid and blood-brain barriers may be more vulnerable to the passage of certain substances or toxins than those of adults We found that some antigens which reach the brain can produce a rapid and powerfu antibody response. ${ }^{4}$ The possibility exists that the encephalitis syndrome both in children and in rabbits is the result of a severe antigen-antibody reaction. It seems likely that the animal experiments described could assist in elucidating the cause of Reye's syndrome and particularly in testing therapeutic measures.-I am, etc.,

Prince of Wales's General Hospital,

A. Elkeles

1 Friedemann, U., and Elkeles, A., British Medical fournal, 1933, 2 , 1110

denoma, M. H., in Rose Research on Lymphadenoma, p. 7. Bristol, John Wright, 1932.
Gordon, M. H., British Medical Joumal, 1, 641.

Friedemann, U., and Elkeles, A., Klinische
Wochenschrift, 1930, 9, 1907.

\section{Erudition and Aphorisms}

SIR, - While your erudite readers are beautifically browsing in the lush fields of psychosomatic derivations (1 September, p. 503) will they please keep at least one eye open for the origin of yet another phrase?

"It is much more important to know what sort of a patient has a disease, than what sort of a disease the patient has." This classical sounding aphorism has been attributed in print to Caleb Hillier Parry (17751822) of Bath, who described Graves's disease long before Graves. I fell into a trap many years ago: having seen the attribution I was not alone in repeating it. My subsequent mortification at not being able to discover the phrase in Parry's writings has not been assuaged over the years by taxing other culprits and putting them in the same embarrassing position. etc.,

Will some scholar please oblige?-I am, Royal Hospital for Sick Children,
Bristol

JOHN APLEY

\section{Problem Oriented Record Card}

SIR,-An extension of the problem oriented card in general practice records is to initiate it when conception is first confirmed. During pregnancy it could be kept with the maternity co-operation card until the baby has a folder of his own. This procedure should be followed in all pregnancies, whether there are problems or not, and in the event of miscarriage the record would simply be destroyed. Such a record would seem to be a useful tool for the prospective investigation of carcinogenicity and teratogenicity as well as being a reminder of "at risk" factors. A variant of the adult problem oriented card is easily devised.-I am, etc.,

Abbotts Langley, Herts 